\title{
GESTÃO AMBIENTAL DE RECURSOS HUMANOS E NÍVEL DE ENVOLVIMENTO DE COLABORADORES NAS ORGANIZAÇÕES
}

\section{JOSE ALBERTO CAMARGO}

Mestre em Economia pelo Programa de Pós-Graduação em Economia da Universidade Estadual Paulista (Unesp). Pesquisador e doutorando em Administração pelo Programa de Pós-Graduação em Administração de Organizações da Faculdade de Economia, Administração e Contabilidade da Universidade de São Paulo (USP-Ribeirão Preto). Avenida Bandeirantes, 3.900, Monte Alegre, Ribeirão Preto - SP - Brasil - CEP 14040-905

E-mail: josealcam@uol.com.br

\section{LARA BARTOCCI LIBONI}

Doutora em Administração pela Faculdade de Economia, Administração e Contabilidade da Universidade de São Paulo (USP).

Professora do Departamento de Administração da Faculdade de Economia, Administração e Contabilidade da Universidade de São Paulo (USP-Ribeirão Preto). Avenida Bandeirantes, 3.900, Monte Alegre, Ribeirão Preto - SP - Brasil - CEP 14040-905

E-mail: lara.liboni@gmail.com

\section{JORGE HENRIQUE CALDEIRA DE OLIVEIRA}

Doutor em História pela Faculdade de Ciências Humanas e Sociais da Universidade Estadual Paulista (Unesp).

Professor do Departamento de Administração da Faculdade de Economia, Administração e Contabilidade da Universidade de São Paulo (USP-Ribeirão Preto). Avenida Bandeirantes, 3.900, Monte Alegre, Ribeirão Preto - SP - Brasil - CEP 14040-905

E-mail: jorgecaldeira@usp.br 


\section{RESUMO}

O objetivo deste artigo é propor indicadores que possibilitem fazer uma aproximação entre envolvimento de colaboradores e gerenciamento de projetos ambientais realizados nas organizações. Os indicadores desenvolvidos têm a finalidade de mensurar o nível de comprometimento de colaboradores e organização na promoção de projetos relacionados à gestão ambiental. Trata-se, portanto, de uma pesquisa de caráter teórico-empírica. Tais indicadores podem, futuramente, compor uma escala que auxilie a compreensão da efetividade desses projetos ambientais, de modo a envolver funcionários da organização desde o planejamento até a condução e os resultados. Espera-se que as contribuições apresentadas sejam úteis para pesquisadores, de forma a auxiliá-los a propor novos estudos que possam melhorar os indicadores aqui apresentados, além de permitir que outros estudos apliquem esses indicadores em organizações públicas ou privadas.

\section{PALAVRAS-CHAVE}

Colaboradores. Gerenciamento de projetos ambientais. Green HRM. Sustentabilidade. Indicadores.

\section{INTRODUÇÃO}

A partir dos conceitos de responsabilidade social corporativa (RSC), proposto por Carroll (I979), e de sustentabilidade empresarial, defendido por Elkington (200I), muitos trabalhos (Hind, Wilson, \& Lenssen, 2007; Jabbour \& Santos, 2008; Jackson \& Seo, 20I0; Jackson, Renwick, Jabbour, \& Muller-Camen, 20II) passaram a se preocupar com a gestão de recursos humanos sustentáveis na 
organização, considerando aspectos que integram essa área de pesquisa com a área de gestão ambiental, conceito conhecido na literatura por Green Human Resource Management (Green HRM).

O conceito de Green HRM traz contribuições fundamentais para pensar o envolvimento entre funcionários e a gestão de uma organização sustentável, não incluindo, portanto, a participação dos demais stakeholders ligados à empresa ao propor novos projetos ambientais desenvolvidos por ela. Os trabalhos relacionados ao Green HRM estabelecem, portanto, uma ligação entre a gestão de recursos humanos e a sustentabilidade.

Nesse mesmo ponto de vista, Jackson et al. (20II) expõem que uma das linhas a seguir para pesquisas futuras deveria envolver a gestão de recursos humanos relacionada à sustentabilidade, destacando dez possibilidades de pesquisa, das quais seis são listadas a seguir:

I. Pesquisa de estratégia de negócios e desempenho.

2. Estudo de incentivos a funcionários que auxiliem a organização a ter melhores práticas ambientais.

3. Pesquisas que investiguem incentivos a funcionários que auxiliem a organização a ter melhores práticas ambientais.

4. Estudos que proponham métricas que permitam aos empregados verificar o desempenho da organização.

5. Pesquisas que proponham respostas positivas aos funcionários da organização em relação a práticas ambientais.

6. Estudos que investiguem o gerenciamento ambiental ligado aos recursos humanos, além das fronteiras nacionais, e que envolvam o esforço de empresas multinacionais para desenvolver políticas ambientais e de recursos humanos inter-relacionadas em vários países.

A escolha da apresentação dessas seis possibilidades, citadas pelos autores, deve-se ao fato de que elas se encontram em consonância com a dificuldade de encontrar, na literatura, indicadores que consigam captar o envolvimento de funcionários com a área de gestão ambiental dentro da organização. Este artigo visa sugerir, portanto, indicadores de gestão que possam atender a essa lacuna, sendo essa a sua proposição principal. 


\section{UMA BREVE DISCUSSÃO SOBRE SUSTENTABILIDADE, RESPONSABILIDADE SOCIAL CORPORATIVA E GESTÃO DE RECURSOS HUMANOS SUSTENTÁVEIS (GREEN HUMAN RESOURCES MANAGEMENT - GHRM)}

O debate sobre sustentabilidade e RSC passou a ganhar grande destaque na academia a partir da definição de RSC dada por Carroll (I979), cujo modelo conceitual desenvolvido se tornou a base de muitos modelos de gestão ambiental.

Segundo Carroll (I979), a RSC compreende quatro expectativas ou dimensões que a sociedade tem em relação às organizações num dado período: econômicas, legais, éticas e discricionárias. Essas quatro dimensões são as responsabilidades da empresa que foram apresentadas em forma de pirâmide, em que cada dimensão ocupa um nível, da base até o topo.

Conforme Carroll (I979), a empresa deve ser primeiramente lucrativa (responsabilidade econômica). Depois, ela deve respeitar as leis vigentes e obedecer a elas (responsabilidade legal) e fazer aquilo que é correto, minimizando os danos que podem impactar as pessoas (responsabilidade ética), mesmo que tais ações não estejam previstas na legislação.

A última dimensão é caracterizada pelas responsabilidades discricionárias, expressão que foi substituída por responsabilidades filantrópicas em I99i pelo mesmo autor. Segundo Carroll (I99I), essa dimensão da responsabilidade social inclui iniciativas que tornam a empresa comprometida com ações de cidadania, atendendo a expectativas que provêm da sociedade. Nesse quesito, o comprometimento da empresa em suas ações e programas deve buscar sempre o bem-estar do ser humano.

Ainda sobre a questão da sustentabilidade ligada à RSC, Marrewijk (2003) expõe que o objetivo da empresa sustentável é contribuir para o desenvolvimento, e, para isso, ela se vale da responsabilidade social para que essa contribuição seja efetiva.

Um modelo de sustentabilidade bastante utilizado e respeitado é aquele desenvolvido por Elkington (200I), conhecido como o modelo Triple Bottom Line. Esse modelo pressupõe que a responsabilidade social das empresas é um instrumento importante para a superação de crises sociais e ambientais.

No meio empresarial, o modelo Triple Bottom Line ficou conhecido por causa do livro Canibais com garfo e faca, de John Elkington (200I) - do original 
Cannibals with forks, publicado em I997. Nessa obra, Elkington (200I) faz o seguinte questionamento: $\mathrm{O}$ capitalismo se tornaria mais civilizado se usasse as três dimensões propostas no desenvolvimento sustentável?

Neste sentido, ele usa a metáfora: Um canibal se tornaria mais civilizado se usasse garfo?

As três linhas de resultados líquidos correspondem às três dimensões de sustentabilidade da empresa - social, ambiental e econômica - apresentadas em Sachs (I993) a partir da ideia de desagregação do conceito de desenvolvimento sustentável.

O que o modelo de Elkington (200I) traz de novo em relação a Sachs (I993) é a maneira como essas três dimensões são concebidas na esfera organizacional. Elkington (200I) critica a expressão "resultados líquidos", que é familiar dentro dos negócios empresariais, uma vez que a própria contabilidade já a utiliza para se referir ao lucro.

De acordo com Elkington (200I), para a empresa, a busca pelo lucro e pela maximização do seu valor de mercado é reconhecida pela dimensão econômica, mas, quando se trata de desenvolvimento sustentável, o conceito tradicional de lucro contábil não é suficiente. Os capitais físico, financeiro e humano, que formam o capital econômico, precisam ser incluídos nessa discussão com as questões ambientais e sociais.

A partir da busca pelo bem-estar do ser humano na organização, mencionada por Carroll (I99I), Elkington (200I) e, posteriormente, por outros autores, é que se inicia a preocupação de como envolver a área de recursos humanos nas organizações, de forma que elas e seus colaboradores passem a ter uma postura mais proativa.

Essa atitude mais proativa, cujas variáveis foram identificadas na literatura por González Benito e González Benito (2006) e, inicialmente, ligadas à gestão ambiental, levaria esses colaboradores a realizar uma autorreflexão acerca de seus papéis dentro da organização sobre ações e projetos sustentáveis, o que se convencionou chamar de Green HRM ou gestão de recursos humanos na organização, considerando aspectos da sustentabilidade.

Sobre a Green HRM, surgiram muitos artigos teóricos relevantes como o de Hoffman (I993), segundo o qual os valores provenientes dos modelos de gestão ambiental são, de forma geral, inconsistentes com os valores dos funcionários das organizações, o que representa um problema para a gestão de recursos humanos e uma ineficiência da organização ao propor políticas amplas de gestão ambiental que possam ser disseminadas e adotadas por todos os funcionários. 
Com base no argumento de Hoffman (I993), Harris e Crane (2002) apresentam modelos discutidos na literatura sobre gestão ambiental e apontam muitos problemas advindos do fato de esses modelos serem propostos para as organizações de forma centralizada ou de cima para baixo. Esses modelos, segundo Harris e Crane (2002), são praticamente impostos pelos níveis hierárquicos mais altos aos funcionários do "chão de fábrica", o que impossibilita a participação dos colaboradores da empresa.

De acordo com Fernández, Junquera e Ordiz (2003), três questões envolvem a gestão ambiental e a gestão de recursos humanos. A primeira trata das funções gerenciais, ao promover uma gestão de recursos humanos integrada à gestão ambiental.

A segunda questão diz respeito ao papel da cultura organizacional na formação das partes internas interessadas em mudanças na proatividade da organização, em relação a práticas ambientais. Sobre essa questão, Fernández et al. (2003) mostram que a cultura organizacional pode facilitar a adoção de uma estratégia que incentive a formação de stakeholders internos com atitudes proativas em relação a práticas ambientais. Entretanto, a cultura da organização pode ser uma barreira intransponível na mudança de atitude de funcionários em relação a questões ambientais.

Por fim, a terceira questão refere-se ao envolvimento institucional dos funcionários em relação ao meio ambiente. Inicialmente, apresentam-se questionamentos sobre a importância de criar um departamento específico de gestão ambiental nas organizações e também sobre quem deve ser responsável por esse setor.

O trabalho de Hind et al. (2007) considera, principalmente, aspectos qualitativos relacionados ao treinamento e desenvolvimento de líderes que possuam as competências necessárias para garantir a sustentabilidade da empresa, não levando em conta aspectos como recrutamento e seleção, avaliação de desempenho e remuneração.

Destacam-se ainda as contribuições de Jabbour e Santos (2008), que sugerem um modelo teórico de gestão de recursos humanos para desenvolver organizações sustentáveis, construído a partir de evidências empíricas e de constatações da literatura.

Esses últimos autores expõem que a relação entre os recursos humanos e a sustentabilidade organizacional é baseada em aspectos econômicos sociais e ambientais, conforme prevê o Triple Bottom Line proposto por Elkington (200I), além de envolver alguns aspectos importantes relativos à gestão, como inovação, diversidade cultural e meio ambiente. É a integração dos itens do Triple Bottom 
Line com aspectos da gestão que leva ao desenvolvimento de um modelo baseado em uma postura estratégica e central do ser humano e da gestão de recursos, relacionando-os com uma real preocupação com aspectos da sustentabilidade empresarial (Jabbour \& Santos, 2008).

Segundo Jackson e Seo (2010), a eficácia das práticas de recursos humanos é atualmente avaliada com frequência por meio de estimativas de valor econômico agregado ou retorno sobre o investimento. Tais métricas colocam considerável ênfase em custos monetários e retornos financeiros, e refletem grande deferência aos interesses financeiros e dos acionistas e de outros proprietários.

Na visão dos autores, para estudiosos e profissionais estratégicos de gestão de recursos humanos interessados em alcançar a sustentabilidade ambiental, um foco estreito sobre o desempenho financeiro é insuficiente para traçar um panorama da organização focada também em sustentabilidade, sendo necessária possuir familiaridade com uma gama muito mais ampla de métricas de desempenho sustentável para determinar padrões de sustentabilidade.

No entanto, para Jackson e Seo (20I0), a ênfase estratégica de recursos humanos, no uso de gestão de sistemas para melhorar o desempenho da empresa, pode fornecer uma base adequada para uso de gestão verde em recursos humanos no futuro, já que perspectivas ainda teóricas podem ser aplicadas com bastante facilidade nesse domínio em novas pesquisas.

Ainda a respeito de gestão sustentável de recursos humanos, Jackson et al. (20II) expõem que a discussão sobre gerenciamento de recursos humanos e meio ambiente está relacionada a três questões: gestão proativa, impacto ambiental e percepções distintas de diferentes países sobre efeitos danosos dos impactos ambientais.

Embora cada um desses aspectos tenha sua relevância, a construção de indicadores, proposta por este artigo, relaciona-se com o primeiro aspecto aqui apresentado por Jackson et al. (2OII), ou seja, o aspecto da gestão proativa ou da proatividade da organização, considerando, assim, a sugestão de um instrumento que permita operacionalizá-la.

No presente trabalho, considera-se que a proatividade, também mencionada em González Benito e González Benito (2006), relaciona-se com o grau de envolvimento entre a organização e os projetos ambientais que ela gerencia, mas essa relação depende do grau de envolvimento dos funcionários conscientes, a partir das considerações de uma gestão baseada no Green HRM e nos demais stakeholders. 


\section{PREMISSAS UTILIzAdAS PARA A CONSTRUÇÃO DE INDICADORES DE ENVOLVIMENTO DE COLABORADORES EM GESTÃO DE PROJETOS AMBIENTAIS NAS ORGANIZAÇÕES}

A fim de sugerir a operacionalização de métricas que permitam a gerentes e empregados verificar o desempenho da organização, conforme sugerem Jackson et al. (20II), e atender, assim, ao objetivo principal deste estudo, diversos estudos teóricos discutidos na literatura, bem como as proposições das normas dos Accountability Principles Standard ı००० (AAıо००) e da International Organization for Standardization 26000 (ISO 26000), foram analisados, com a finalidade de construir e propor uma métrica que envolva as gestões de recursos humanos e ambiental. A seguir, fazem-se breves comentários sobre essas normas, cujas proposições foram utilizadas na construção dos indicadores de gestão de projetos ambientais apresentados neste artigo.

A AAıooo (Accountability Principles Standard, 2008) é uma norma voluntária de aprimoramento da organização, cujo princípio é assegurar a qualidade da contabilidade, da auditoria e dos relatos social, ambiental e ético. É composta por princípios e um conjunto de padrões de processos.

A AAıоoo objetiva apoiar a aprendizagem organizacional e o desempenho geral (social e ético, ambiental e econômico) e, portanto, a contribuição da organização em direção ao caminho do desenvolvimento sustentável.

Já a ISO 26000 (International Organization for Standardization, 2009) expõe que as decisões e atividades da organização, invariavelmente, têm um impacto no meio ambiente, independentemente de onde a empresa esteja localizada. Esses impactos podem estar associados ao uso, por parte da organização, de recursos vivos e não vivos, à localização de suas atividades, à geração de poluição e resíduos e às implicações de suas atividades, produtos e serviços nos hábitats naturais.

A norma recomenda que, para reduzir seus impactos ambientais, é importante que a organização adote uma abordagem integrada que leve em consideração as implicações econômicas e socioambientais mais amplas de suas decisões e atividades.

Para Barbieri e Cajazeira (20I0), a ISO 26000 difere das demais normas, pois ela não tem como objetivo funcionar sozinha. Seu propósito é servir como um documento de integração entre os demais instrumentos de gestão já existentes.

A ISO 26000 reconhece a importância e as contribuições que normas de gestão ambiental e social trazem para a empresa e busca entender que cada uma 
delas abrange apenas alguns requisitos, sendo impossível cobrir todos os tópicos da responsabilidade social. Ela busca ser um guia às organizações de modo que elas I. tenham uma orientação adequada de suas decisões sobre a sua responsabilidade social e 2 . consigam usar todos os instrumentos de gestão disponíveis da melhor maneira possível.

De acordo com Barbieri e Cajazeira (20I0), em I999, o Institute of Social \& Ethical Accountability criou a norma AAıooo. Dentre todas as já apresentadas, o que torna essa norma especial é a sua flexibilidade e o fato de ela ser voluntária e não certificável. Sua flexibilidade vem da sua capacidade de ser usada isoladamente ou em combinação com outras normas ou padrões já existentes. Essas especificações contribuíram para que ela fosse a mais adequada dentro dos propósitos definidos neste presente trabalho para auxiliar na proposição de indicadores.

Segundo a AArooo (Accountability Principles Standard, 2008), uma norma de autogestão deve ser desenvolvida para assegurar a qualidade e a credibilidade do desempenho em sustentabilidade, bem como a elaboração de relatórios de sustentabilidade. Essa norma deve ser resultante de um processo abrangente de pesquisa que levou em consideração os diversos stakeholders de diferentes setores, o que torna evolutivo esse aprendizado e, consequentemente, contínuo o processo de elaboração de normas.

Também a credibilidade é um pré-requisito para a elaboração eficaz de relatórios de sustentabilidade. A credibilidade pode ser consideravelmente melhorada por meio de um processo independente e externo de creditação, utilizando normas profissionais.

De acordo com a AAıooo (Accountability Principles Standard, 2008), as responsabilidades social e, por conseguinte, ambiental consistem na capacidade de resposta de uma organização às preocupações das partes interessadas que afetam o seu desempenho sustentável e são concretizadas por meio de decisões, ações e desempenho, bem como pela comunicação com os stakeholders.

Nesse sentido, uma organização comunica as suas respostas às necessidades e expectativas das partes interessadas, de modo a permitir a tomada de decisões fundamentadas. Além disso, a organização procura obter as competências e capacidades necessárias, bem como estabelecer os processos para alcançar as respostas com as quais se comprometeu.

Apesar de a norma AAıooo (Accountability Principles Standard, 2008) destacar que a organização deve comunicar as suas respostas às necessidades e expectativas das partes interessadas, ela não diz como a organização deve fazer isso. Com base nessa lacuna, este estudo propõe indicadores que consigam atender ao objetivo de mensurar o envolvimento entre a gestão de projetos sociais e os colaboradores da organização. 


\section{CRITÉRIOS UTILIZADOS NA CONSTRUÇÃO DE INDICADORES PARA A GESTÃO DE PROJETOS AMBIENTAIS ENVOLVENDO COLABORADORES}

A partir da busca de variáveis que pudessem auxiliar a proposição de indicadores, visando acompanhar projetos ambientais na organização, observaram-se o trabalho de González Benito e González Benito (2006) e sua proposição de variáveis para uma empresa proativa no que diz respeito à condução de sua gestão ambiental.

González Benito e González Benito (2006) apresentam o conceito de proatividade ambiental como sendo de implantação voluntária por parte das organizações. Nessa concepção, esse conceito dependeria de um sistema de gerenciamento ambiental (Environmental Management System - EMS), cuja função seria a de definir a política ambiental da empresa, sua responsabilidade e coordenação. Os autores apresentam a ideia de que a pressão exercida por stakeholders, entre eles os colaboradores da organização, é tão relevante quanto quaisquer outras variáveis que afetam a empresa em sua decisão de perseverar em práticas ambientalmente corretas.

González Benito e González Benito (2006) apresentam ainda um esquema de fatores determinantes na gestão ambiental, destacando a proatividade ambiental como sendo dividida nas áreas de operações, planejamento e organização e comunicação.

Destaca-se ainda que há fatores exógenos à vontade da empresa em promover política proativa ambiental que devem ser considerados (características da empresa em relação a sistemas gerenciais e tecnologia, pressão dos stakeholders, além de fatores externos tais como setor da indústria e localização geográfica).

Com base nessas observações, buscou-se apresentar indicadores que envolvessem as áreas de gestão de recursos humanos e de gestão ambiental. Os indicadores e a métrica apresentados a seguir foram construídos a partir da realização da integração da literatura com as normas ISO 26000 e AAiooo, bem como da necessidade prática de propor indicadores que auxiliem o gerenciamento das empresas na área de recursos humanos integrada ao meio ambiente.

Quando uma empresa faz uso de indicadores para medir o seu desempenho em nível de clientes, de processos e em âmbito global, nas palavras de Tachizawa (20II), isso se constitui um "fator fundamental para a organização viabilizar a adoção da configuração organizacional por processos conjugada à estrutura vertical (estrutura funcional ou tradicional)". 
É necessário, porém, que a organização, num primeiro momento, compare seus indicadores de desempenho internos com indicadores padrão externos à empresa que são divulgados por associações, entidades de classes, sindicatos, órgãos governamentais e publicações especializadas, fazendo os ajustes necessários para que tais indicadores possam ser comparados corretamente.

Além disso, eles devem ser fáceis de ser compreendidos e precisos nas suas definições para que seus significados sejam interpretados de uma mesma maneira dentro dos diferentes departamentos ou setores da empresa.

Essa ideia, exposta por Tachizawa (20II), também é defendida pela AAıooo (Accountability Principles Standard, 2008) e por O'Connor e Spangenberg (2008), que afirmam que tais indicadores devem ser fáceis de ser aplicados e de compreensão simplificada.

Ainda de acordo com Tachizawa (20II), quando as métricas são estabelecidas na forma de indicadores de desempenho, o gerenciamento do desempenho na empresa é assegurado, os problemas e a ordem das prioridades são identificados, os funcionários passam a ter uma clara compreensão daquilo que a empresa espera deles e programas de incentivos e recompensas são estabelecidos de maneira objetiva, justa e igualitária.

O Quadro I apresenta o resumo dos trabalhos de diversos autores que trazem contribuições à metodologia da mensuração e eficácia de projetos de responsabilidade social.

\section{QUADRO I}

ESTUDOS REALIZADOS SOBRE METODOLOGIAS REFERENTES A MENSURAÇÃO DA EFICÁCIA DE RESPONSABILIDADE SOCIAL

\begin{tabular}{|c|c|c|c|}
\hline AUTORES & CONTRIBUIÇÃO PARA A ÁREA DE CONHECIMENTO & $\begin{array}{l}\text { MÉTODO DE } \\
\text { PESQUISA }\end{array}$ & $\begin{array}{l}\text { PAÍS DE } \\
\text { ORIGEM }\end{array}$ \\
\hline $\begin{array}{c}\text { Tencati, } \\
\text { Perrini e } \\
\text { Pogutz } \\
\text { (2004) }\end{array}$ & $\begin{array}{l}\text { Os autores apresentam as vantagens para } \\
\text { empresas, cidadãos e governo, obtidas a partir } \\
\text { dos resultados conseguidos por uma iniciativa } \\
\text { promovida pelo governo italiano, chamada } \\
\text { Responsabilidade Social Empresarial - } \\
\text { Engajamento Social (RSE-ES). Essa iniciativa } \\
\text { foi coordenada pela Universidade de Bocconi. } \\
\text { O estudo desses autores faz uma revisão } \\
\text { das diferentes metodologias que podem ser } \\
\text { utilizadas para dar suporte à ação conjunta } \\
\text { entre governo, universidade e iniciativa privada. }\end{array}$ & $\begin{array}{l}\text { - Teórico- } \\
\text {-empírico } \\
\text { - Estudo de } \\
\text { caso com } \\
\text { uma amostra } \\
\text { de } 395 \\
\text { empresas com } \\
\text { aplicação de } \\
\text { questionários }\end{array}$ & Holanda \\
\hline
\end{tabular}

(continua) 
QUADRO I (CONTINUAÇÃO)

ESTUDOS REALIZADOS SOBRE METODOLOGIAS REFERENTES A MENSURAÇÃO DA EFICÁCIA DE RESPONSABILIDADE SOCIAL

\begin{tabular}{|c|c|c|c|}
\hline AUTORES & CONTRIBUIÇÃO PARA A ÁREA DE CONHECIMENTO & $\begin{array}{l}\text { MÉTODO DE } \\
\text { PESQUISA }\end{array}$ & $\begin{array}{l}\text { PAÍS DE } \\
\text { ORIGEM }\end{array}$ \\
\hline $\begin{array}{l}\text { Vuontisjarvi } \\
\text { (2006) }\end{array}$ & $\begin{array}{l}\text { Com base em relatórios anuais de } 205 \\
\text { empresas finlandesas, buscou-se mensurar } \\
\text { o nível de RSE, analisando apenas a área } \\
\text { de comunicação social, ligado a recursos } \\
\text { humanos. Considerando que o tema ainda } \\
\text { é novo na Finlândia e que muitas empresas } \\
\text { ainda desconhecem o conceito de RSE, há } \\
\text { necessidade de melhorias na qualidade da } \\
\text { divulgação das informações contidas nos } \\
\text { relatórios dessas empresas. }\end{array}$ & $\begin{array}{l}\text { - Teórico- } \\
\text {-empírico, } \\
\text { com base em } \\
\text { relatórios anuais } \\
\text { sobre RSE das } \\
205 \text { maiores } \\
\text { empresas } \\
\text { finlandesas com } \\
\text { pelo menos } 200 \\
\text { empregados } \\
\text { em } 2000\end{array}$ & $\begin{array}{l}\text { Reino } \\
\text { Unido }\end{array}$ \\
\hline $\begin{array}{l}\text { Hutchins e } \\
\text { Sutherland } \\
\text { (2008) }\end{array}$ & $\begin{array}{l}\text { Os autores demonstram que a decisão individual } \\
\text { de uma empresa pode afetar significativamente } \\
\text { as medidas nacionais de sustentabilidade. Para } \\
\text { isso, propuseram-se diversos indicadores de } \\
\text { sustentabilidade social, que foram aplicados } \\
\text { posteriormente a uma empresa, para demonstrar } \\
\text { como as decisões corporativas podem ser } \\
\text { tomadas para melhorar a sustentabilidade social } \\
\text { de toda uma cadeia de suprimentos. Os autores } \\
\text { reconhecem que é um desafio operacionalizar } \\
\text { indicadores de sustentabilidade social que } \\
\text { orientem as decisões das empresas no que diz } \\
\text { respeito à seleção de seus fornecedores dentro } \\
\text { da cadeia de suprimentos. }\end{array}$ & $\begin{array}{l}\text { - Teórico- } \\
\text {-empírico, } \\
\text { com revisão } \\
\text { da literatura e } \\
\text { utilização de } \\
\text { um exemplo } \\
\text { real }\end{array}$ & $\begin{array}{l}\text { Estados } \\
\text { Unidos }\end{array}$ \\
\hline $\begin{array}{c}\text { O'Connor e } \\
\text { Spangenberg } \\
(2008)\end{array}$ & $\begin{array}{l}\text { Os autores propõem uma metodologia geral } \\
\text { para o desenvolvimento de uma estrutura de } \\
\text { RSE, abordando quatro aspectos: identificação } \\
\text { de problemas, diálogo das partes interessadas, } \\
\text { seleção de indicadores e construção de relatórios. } \\
\text { Os autores também discutem critérios para criar } \\
\text { bons indicadores sociais. A metodologia, após } \\
\text { seu desenvolvimento, foi utilizada para verificar } \\
\text { avanços na responsabilidade social de empresas } \\
\text { de alumínio na Europa. }\end{array}$ & $\begin{array}{l}\text { - Teórico- } \\
\text {-empírico }\end{array}$ & $\begin{array}{c}\text { França/ } \\
\text { Alemanha }\end{array}$ \\
\hline
\end{tabular}

(continua) 
QUADRO I (CONCLUSÃO)

ESTUDOS REALIZADOS SOBRE METODOLOGIAS REFERENTES A MENSURAÇÃO DA EFICÁCIA DE RESPONSABILIDADE SOCIAL

\begin{tabular}{|c|c|c|c|}
\hline AUTORES & CONTRIBUIÇÃO PARA A ÁREA DE CONHECIMENTO & $\begin{array}{l}\text { MÉTODO DE } \\
\text { PESQUISA }\end{array}$ & $\begin{array}{l}\text { PAÍS DE } \\
\text { ORIGEM }\end{array}$ \\
\hline $\begin{array}{c}\text { Tachizawa } \\
\text { (2011) }\end{array}$ & $\begin{array}{l}\text { O autor discute quais os elementos estruturais } \\
\text { devem estar contidos na arte da gestão } \\
\text { ambiental e de responsabilidade social, } \\
\text { dando destaque à inferência científica, já que } \\
\text { esta pode auxiliar na verificação de como as } \\
\text { decisões são tomadas e como elas impactam } \\
\text { o meio ambiente. Diante disso, é proposta a } \\
\text { utilização de "indicadores de gestão ambiental } \\
\text { e de responsabilidade social" para medir, em } \\
\text { termos quantitativos, os resultados reais de uma } \\
\text { empresa ou os atributos de um determinado } \\
\text { processo ocorrido com aqueles que foram } \\
\text { preestabelecidos como metas a serem atingidas } \\
\text { ou determinadas como padrões ideais. }\end{array}$ & $\begin{array}{l}\text { - Teórico- } \\
\text {-empírico }\end{array}$ & Brasil \\
\hline
\end{tabular}

Fonte: Elaborado pelos autores.

\section{PROPOSTA DE INDICADORES DE PROJETOS AMBIENTAIS COM BASE NO CONCEITO DE PROATIVIDADE AMBIENTAL}

Esta seção apresenta alguns indicadores desenvolvidos pelos autores que levam em consideração diversos aspectos para a sua construção, já comentados neste artigo, tais como:

- trabalhos teóricos sobre sustentabilidade;

- trabalhos teóricos que trazem a ligação entre a área de recursos humanos e a área de gestão ambiental;

- variáveis de proatividade ambiental apresentadas por González-Benito e González-Benito (2006);

- necessidade operacional das organizações em medir sua eficácia em projetos ambientais, levando em conta o nível de envolvimento de seus funcionários e;

- normas ISO 26000 e AAiooo. 
O Quadro 2 apresenta a descrição dos indicadores referentes a cada etapa da gestão da responsabilidade ambiental da organização. O quadro mostra o indicador que está sendo medido, sua forma operacional e seu significado.

QUADRO 2

\section{RESPONSABILIDADE AMBIENTAL E ENVOLVIMENTO DE RECURSOS HUMANOS}

\begin{tabular}{|c|c|c|c|c|}
\hline ETAPAS & VARIÁVEL & INDICADOR & $\begin{array}{l}\text { FORMA OPERACIONAL } \\
\text { DO INDICADOR }\end{array}$ & $\begin{array}{l}\text { INTERPRETAÇÃO } \\
\text { DO INDICADOR }\end{array}$ \\
\hline \multicolumn{5}{|l|}{$\begin{array}{l}\text { Etapa 1: gestão reativa } \\
\text { de projetos ambientais }\end{array}$} \\
\hline \multirow{4}{*}{$\begin{array}{l}\text { Etapa em que a } \\
\text { organização começa } \\
\text { a promover ações } \\
\text { de responsabilidade } \\
\text { ambiental vinculadas } \\
\text { a comissões de } \\
\text { funcionários. }\end{array}$} & \multirow[b]{2}{*}{$\begin{array}{l}\text { Participação dos } \\
\text { funcionários }\end{array}$} & $\begin{array}{l}1 \text { A-1: indicador } \\
\text { de cooperação } \\
\text { da instituição } \\
\text { (funcionários) } \\
\text { (ICF) }\end{array}$ & $\begin{array}{l}\text { ICF: número de funcionários } \\
\text { envolvidos diretamente nos } \\
\text { projetos ambientais/número } \\
\text { de funcionários na empresa. }\end{array}$ & $\begin{array}{l}\text { Indica: número de } \\
\text { funcionários envolvidos } \\
\text { diretamente nos projetos } \\
\text { ambientais em proporção } \\
\text { ao número total de } \\
\text { funcionários em cada } \\
\text { empresa. }\end{array}$ \\
\hline & & $\begin{array}{l}\text { 1A-2: indicador } \\
\text { de cooperação } \\
\text { da instituição } \\
\text { (voluntários) } \\
\text { (ICV) }\end{array}$ & $\begin{array}{l}\text { ICV: número de voluntários } \\
\text { envolvidos diretamente nos } \\
\text { projetos ambientais/número } \\
\text { de voluntários ligados a } \\
\text { empresa. }\end{array}$ & $\begin{array}{l}\text { Indica: número de } \\
\text { voluntários envolvidos } \\
\text { diretamente nos projetos } \\
\text { ambientais em proporção } \\
\text { ao número total de } \\
\text { voluntários ligados a } \\
\text { empresa. (O voluntário } \\
\text { é a pessoa que coopera } \\
\text { com o trabalho no projeto } \\
\text { ambiental semanalmente, } \\
\text { por um período mínimo } \\
\text { de quatro horas semanais, } \\
\text { sem remuneração.) }\end{array}$ \\
\hline & Variável 1B & \multirow[b]{2}{*}{$\begin{array}{l}\text { 1B-1: indicador } \\
\text { de número de } \\
\text { propostas anuais } \\
\text { para projetos } \\
\text { ambientais (IPA) }\end{array}$} & \multirow[b]{2}{*}{$\begin{array}{l}\text { IPA: número de projetos } \\
\text { ambientais propostos } \\
\text { anualmente pela empresa, } \\
\text { ligados aos projetos } \\
\text { ambientais/número de } \\
\text { projetos ambientais } \\
\text { implantados a partir dessas } \\
\text { propostas na empresa. }\end{array}$} & \multirow[b]{2}{*}{$\begin{array}{l}\text { Indica: número de } \\
\text { projetos ambientais } \\
\text { propostos anualmente } \\
\text { pela empresa em } \\
\text { proporção ao número de } \\
\text { projetos ambientais que } \\
\text { a unidade implantou a } \\
\text { partir dessas propostas. }\end{array}$} \\
\hline & $\begin{array}{l}\text { A organização está } \\
\text { aberta às críticas } \\
\text { dos colaboradores. }\end{array}$ & & & \\
\hline
\end{tabular}


QUADRO 2 (CONTINUAÇÃO)

\section{RESPONSABILIDADE AMBIENTAL E ENVOLVIMENTO DE RECURSOS HUMANOS}

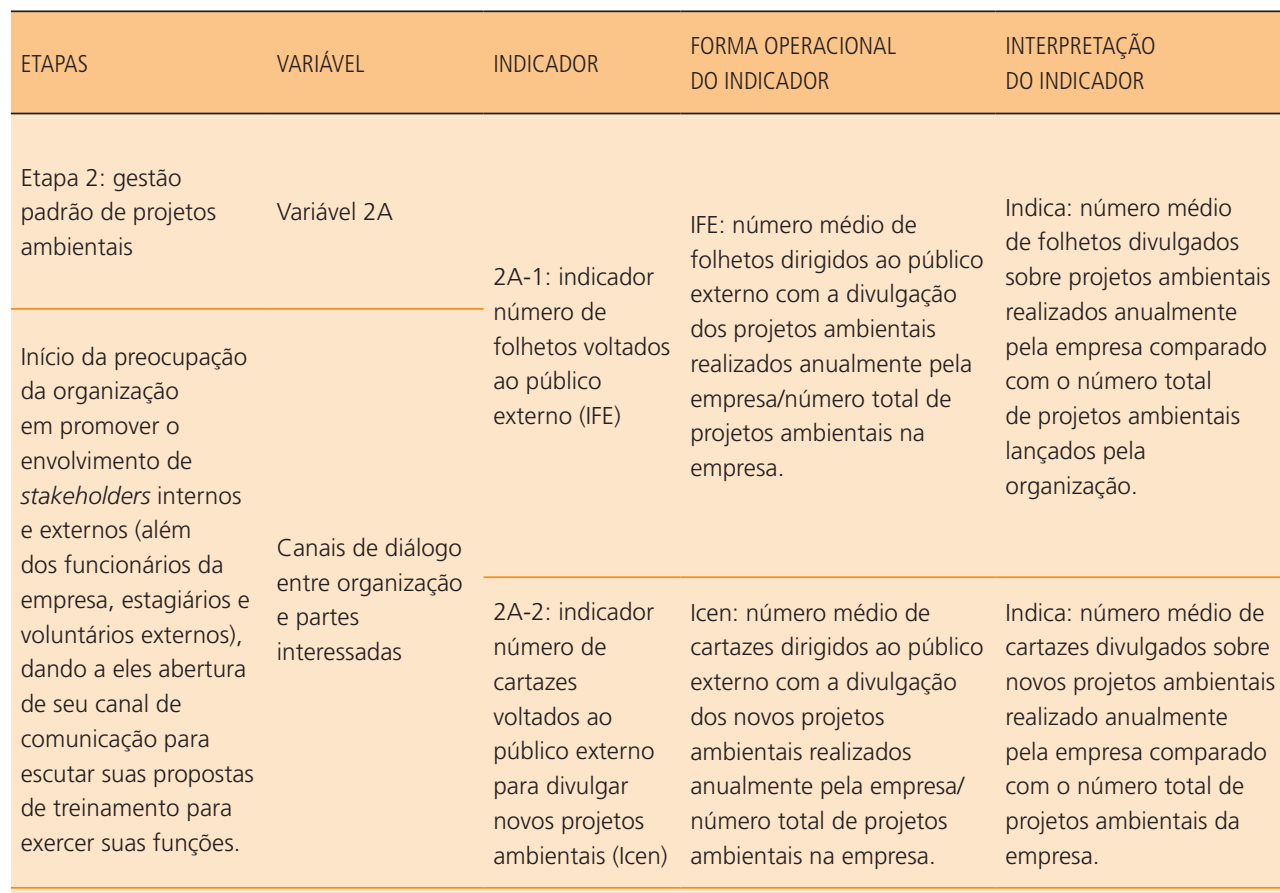

\begin{tabular}{|c|c|c|c|c|}
\hline \multirow{3}{*}{$\begin{array}{l}\text { Início da preocupação } \\
\text { da organização } \\
\text { em promover o } \\
\text { envolvimento de } \\
\text { stakeholders internos } \\
\text { e externos (além } \\
\text { dos funcionários da } \\
\text { empresa, estagiários e } \\
\text { voluntários externos), } \\
\text { dando a eles abertura } \\
\text { de seu canal de } \\
\text { comunicação para } \\
\text { escutar suas propostas } \\
\text { de treinamento para } \\
\text { exercer suas funções. }\end{array}$} & Variável 2B & \multirow[b]{2}{*}{$\begin{array}{l}\text { 2B-1: indicador } \\
\text { de reuniões e } \\
\text { palestras ligadas } \\
\text { a projetos } \\
\text { ambientais } \\
\text { feitas com a } \\
\text { comunidade } \\
\text { (IRC) }\end{array}$} & \multirow[b]{2}{*}{$\begin{array}{l}\text { IRC: número de reuniões } \\
\text { e palestras ligadas a } \\
\text { projetos ambientais no } \\
\text { ano/número de projetos } \\
\text { ambientais promovidos pela } \\
\text { organização. }\end{array}$} & \multirow[b]{2}{*}{$\begin{array}{l}\text { Indica: número de } \\
\text { reuniões e palestras } \\
\text { ligadas a projetos } \\
\text { ambientais no ano em } \\
\text { relação ao número de } \\
\text { projetos ambientais } \\
\text { promovidos pela } \\
\text { organização. }\end{array}$} \\
\hline & $\begin{array}{l}\text { Participação de } \\
\text { grupo comunitário } \\
\text { na elaboração e } \\
\text { implementação } \\
\text { de projetos } \\
\text { ambientais } \\
\text { e realização } \\
\text { de reuniões } \\
\text { periódicas com } \\
\text { representantes das } \\
\text { comunidades }\end{array}$ & & & \\
\hline & $\begin{array}{l}\text { Promove } \\
\text { treinamento } \\
\text { focado nas tarefas } \\
\text { especificadas para } \\
\text { cada função da } \\
\text { área ambiental. }\end{array}$ & $\begin{array}{l}2 \mathrm{C}-1 \text { : indicador } \\
\text { de número de } \\
\text { treinamentos } \\
\text { realizados (INTR) }\end{array}$ & $\begin{array}{l}\text { INTR: número de } \\
\text { treinamentos realizados ao } \\
\text { longo de um ano ligados } \\
\text { a projetos ambientais na } \\
\text { organização/número total } \\
\text { de projetos ambientais. }\end{array}$ & $\begin{array}{l}\text { Indica: número de } \\
\text { treinamentos em um } \\
\text { ano ligados a projetos } \\
\text { ambientais em relação ao } \\
\text { número total de projetos } \\
\text { ambientais existentes na } \\
\text { organização. }\end{array}$ \\
\hline
\end{tabular}


QUADRO 2 (CONCLUSÃO)

\section{RESPONSABILIDADE AMBIENTAL E ENVOLVIMENTO DE RECURSOS HUMANOS}

\begin{tabular}{|c|c|c|c|c|}
\hline ETAPAS & VARIÁVEL & INDICADOR & $\begin{array}{l}\text { FORMA OPERACIONAL } \\
\text { DO INDICADOR }\end{array}$ & $\begin{array}{l}\text { INTERPRETAÇÃO } \\
\text { DO INDICADOR }\end{array}$ \\
\hline $\begin{array}{l}\text { Etapa 3: gestão } \\
\text { proativa de projetos } \\
\text { ambientais }\end{array}$ & Variável 3A & \multirow{2}{*}{$\begin{array}{l}\text { 3A-1: Indicador } \\
\text { de número de } \\
\text { participantes } \\
\text { treinados } \\
\text { para ouvir } \\
\text { sugestões dadas } \\
\text { por usuário } \\
\text { do projeto } \\
\text { ambiental (Ipup) }\end{array}$} & \multirow{2}{*}{$\begin{array}{l}\text { Ipup: número de } \\
\text { participantes do projeto } \\
\text { que foram treinados para } \\
\text { ouvir e levar adiante as } \\
\text { demandas dos usuários } \\
\text { dos projetos/número total } \\
\text { de funcionários envolvidos } \\
\text { com projetos ambientais na } \\
\text { empresa. }\end{array}$} & \multirow{2}{*}{$\begin{array}{l}\text { Indica: número de } \\
\text { participantes do projeto } \\
\text { que foram treinados para } \\
\text { ouvir e levar as demandas } \\
\text { dos usuários dos } \\
\text { projetos ambientais ao } \\
\text { conhecimento da direção } \\
\text { da empresa em proporção } \\
\text { ao número total de } \\
\text { funcionários envolvidos } \\
\text { nos projetos. }\end{array}$} \\
\hline \multirow{2}{*}{$\begin{array}{l}\text { Engajamento de } \\
\text { cada unidade } \\
\text { da organização } \\
\text { ao responder às } \\
\text { demandas de } \\
\text { stakeholders e buscar } \\
\text { processos contínuos } \\
\text { de aperfeiçamento e } \\
\text { eficiência operacional } \\
\text { na gestão de projetos } \\
\text { ambientais. }\end{array}$} & \multirow{2}{*}{$\begin{array}{l}\text { Stakeholders } \\
\text { consideram } \\
\text { qualidade } \\
\text { de projetos } \\
\text { ambientais da } \\
\text { organização } \\
\text { adequados. }\end{array}$} & & & \\
\hline & & $\begin{array}{l}\text { 3A-2: indicador } \\
\text { de participantes } \\
\text { representantes } \\
\text { comunitários na } \\
\text { elaboração, no } \\
\text { planejamento e } \\
\text { na implantação } \\
\text { de projetos } \\
\text { ambientais (Ipre) }\end{array}$ & $\begin{array}{l}\text { Ipre: número de } \\
\text { representantes comunitários } \\
\text { envolvidos em projetos } \\
\text { ambientais/número total } \\
\text { de projetos ambientais em } \\
\text { funcionamento na empresa. }\end{array}$ & $\begin{array}{l}\text { Indica: número } \\
\text { de representantes } \\
\text { comunitários } \\
\text { envolvidos em projetos } \\
\text { ambientais em relação } \\
\text { ao número total de } \\
\text { projetos ambientais } \\
\text { em funcionamento na } \\
\text { empresa. }\end{array}$ \\
\hline \multirow{3}{*}{$\begin{array}{l}\text { Engajamento de cada } \\
\text { unidade organização } \\
\text { ao responder às } \\
\text { demandas de } \\
\text { stakeholders e buscar } \\
\text { processos contínuos } \\
\text { de aperfeiçoamento e } \\
\text { eficiência operacional } \\
\text { na gestão de projetos } \\
\text { ambientais. }\end{array}$} & Variável 3B & \multirow[b]{2}{*}{$\begin{array}{l}\text { 3B-1: indicador } \\
\text { realização } \\
\text { de reuniões } \\
\text { periódicas com } \\
\text { representantes } \\
\text { das } \\
\text { comunidades } \\
\text { (IRR) }\end{array}$} & \multirow[b]{2}{*}{$\begin{array}{l}\text { IRR: número médio } \\
\text { de reuniões realizadas } \\
\text { com representantes da } \\
\text { comunidade para discutir } \\
\text { projetos ambientais/período } \\
\text { de } 12 \text { meses. }\end{array}$} & \multirow[b]{2}{*}{$\begin{array}{l}\text { Indica: número médio } \\
\text { de reuniões realizadas } \\
\text { com representantes da } \\
\text { comunidade para discutir } \\
\text { projetos ambientais } \\
\text { (manutenção ou } \\
\text { expansão de projetos ou } \\
\text { implantação de novos } \\
\text { projetos) em } 12 \text { meses. }\end{array}$} \\
\hline & \multirow{2}{*}{$\begin{array}{l}\text { A organização } \\
\text { identifica, } \\
\text { desenvolve } \\
\text { e implanta } \\
\text { estratégias, planos } \\
\text { e modos de } \\
\text { envolvimento dos } \\
\text { colaboradores, } \\
\text { consistentes e } \\
\text { aplicados a toda } \\
\text { organização. }\end{array}$} & & & \\
\hline & & $\begin{array}{l}\text { 3B-2: indicador } \\
\text { de caixas } \\
\text { de sugestão } \\
\text { e críticas } \\
\text { a projetos } \\
\text { ambientais } \\
\text { (IPSC) }\end{array}$ & $\begin{array}{l}\text { IPSC: número de canais de } \\
\text { sugestões que a empresa } \\
\text { disponibiliza/número de } \\
\text { projetos ambientais que } \\
\text { funcionam na empresa. }\end{array}$ & $\begin{array}{l}\text { Indica: número de canais } \\
\text { de sugestões que a } \\
\text { empresa disponibiliza em } \\
\text { relação ao número de } \\
\text { projetos disponíveis na } \\
\text { empresa. }\end{array}$ \\
\hline
\end{tabular}

Fonte: Elaborado pelos autores.

Sobre o Quadro 2, nota-se que os indicadores são apresentados conforme uma hierarquia ou etapa de proatividade na gestão ambiental, conforme descrito em González Benito e González Benito (2006). 
Na etapa 3, que prevê uma gestão proativa de projetos ambientais envolvendo a organização e seus colaboradores, a expectativa é que a organização já tenha alcançado bons resultados em indicadores das etapas anteriores de gestão. Caso contrário, a organização não pode ser considerada proativa na gestão de projetos ambientais a partir de uma ampla gestão de recursos humanos sustentáveis e envolvendo de forma consistente as partes interessadas.

\section{CONCLUSÕES E LIMITAÇÕES DO
ESTUDO}

Uma das limitações deste estudo é que ele não propõe uma métrica na qual os indicadores apresentados possam estar inseridos. Além disso, esses indicadores ainda não foram aplicados a nenhuma organização. Portanto, não é possível saber quais seriam os possíveis valores de referência para cada um deles, o que só ocorrerá caso esses indicadores sejam utilizados e/ou aperfeiçoados por outros estudos que os apliquem em organizações.

Também não é possível dizer se os indicadores aqui propostos são ou podem ser aplicados, sem adaptações, a todos os tipos de organização que realizam a gestão de projetos ambientais e buscam integrar essa gestão com seus colaboradores.

Apesar das limitações aqui apresentadas, este trabalho contribui com avanços para a literatura da área, que apresenta uma lacuna, indicada por Jabbour e Santos (2008), quando destacam a ausência de estudos que contemplem as áreas de recursos humanos e a área de sustentabilidade, simultaneamente. Este trabalho também atende às sugestões de Jackson et al. (20II), principalmente ao propor um estudo exploratório que auxilie a organização a buscar aprofundamento no gerenciamento ambiental ligado a recursos humanos e às partes interessadas.

Buscou-se ainda contribuir com os anseios de Jackson e Seo (2010), que chegam à conclusão de que a literatura acadêmica sobre gestão de recursos humanos estratégicos traz poucas lições para os profissionais enfrentarem o desafio de utilizar processos de avaliação, planejamento, implementação e revisão num sistema de gestão de recursos humanos.

Nesse sentido, o presente trabalho apresenta como contribuição a sugestão de alguns indicadores que visam mensurar o nível de comprometimento do funcionário e da organização na promoção de projetos relacionados à gestão ambiental. O objetivo da apresentação desses indicadores é o de, futuramente, propor uma escala que auxilie a compreensão da efetividade desses projetos 
ambientais, de modo a envolver os colaboradores da organização desde o planejamento até a condução e os resultados.

Finalmente, espera-se que as contribuições desse artigo sejam úteis para pesquisadores de forma a auxiliá-los a propor novos estudos que possam melhorar os indicadores aqui apresentados em diversas organizações. Espera-se também que outros estudos possam aplicar esses indicadores de gestão de projetos sociais nas organizações, auxiliando os gestores de organizações públicas ou privadas a realizar uma gestão de recursos humanos que seja integrada à área de projetos ambientais. E mais: que gestores possam utilizar parte desses indicadores para futuras métricas na gestão de projetos ambientais que envolvam as partes interessadas da organização.

\section{ENVIRONMENTAL MANAGEMENT OF HUMAN RESOURCES AND LEVEL OF EMPLOYEES' ENGAGEMENT IN ORGANIZATIONS}

\section{ABSTRACT}

The aim of this article is to suggest indicators to make a connection between the engagement of employees and the management of environmental projects undertaken in organizations. The indicators developed are intended to measure the level of commitment of employees to the organizations when they promote projects related to environmental management. It is, therefore, a theoretical and empirical study. In the future, such indicators may propose a scale that helps to understand the effectiveness of these environmental projects by engaging employees in the organization, from its planning to its implementation and results. It is hoped that the contributions are useful for researchers so they can propose new studies that can improve the indicators hereby presented, and that they allow other studies to apply these indicators in public or private organizations.

\section{KEYWORDS}

Employees. Environmental Project Management. Green HRM. Sustainability. Indicators. 


\section{GESTIÓN AMBIENTAL DE LOS RECURSOS HUMANOS Y NIVEL DE PARTICIPACIÓN DE LOS TRABAJADORES EN LAS ORGANIZACIONES}

\section{RESUMEN}

El objetivo de este artículo es sugerir la propuesta de indicadores que permitan establecer una conexión entre la participación de los empleados y la gestión de proyectos de medio ambiente realizados en las organizaciones. Los indicadores desarrollados pretenden medir el nivel de compromiso de los empleados y de la organización al promover proyectos relacionados con la gestión ambiental. Para ello, hemos tratado de explorar conceptos clave e ideas sobre Recursos Humanos Sostenibles y los principios básicos de la AA 1000 e ISO 26000 normas, con el fin de basar este estudio. Es, por lo tanto, una encuesta de carácter teórica y empírica. Es, por lo tanto, una investigación académica teórica y empírica. Tales indicadores pueden, en el futuro, proponer una escala que ayude a entender la eficacia de estos proyectos medioambientales involucrando a los empleados en la organización, desde su planificación hasta su realización y resultados. Se espera que las contribuciones presentadas sean útiles para los investigadores con el fin de ayudarles a proponer nuevos estudios que pueden mejorar los indicadores que aquí se presentan, además de permitir que otros estudios apliquen estos indicadores en organizaciones públicas o privadas.

\section{PALABRAS CLAVE}

Empleados. Gestión proyectos ambientales. Green HRM. Sostenibilidad. Indicadores.

\section{REFERÊNCIAS}

Accountability Principles Standard (2008). AAıоoo. Recuperado em 2 abril, 20II, de http://www. accountability2ı.net/uploadedFiles/publications/AAıоooAPS_VersãoBrasiliera.pdf.

Barbieri, J. C., \& Cajazeira, J. E. R. (2010). Responsabilidade social empresarial e empresa sustentável: da teoria à prática. São Paulo: Saraiva.

Carroll, A. B. A. (1979). Three-dimensional conceptual model of corporate social performance. Academy of Management Review, 4(4), 497-505. Recuperado em 20 maio, 20II, de http://www. kantakji.com/fiqh/Files/Companies/ziıg.pdf. 
Carroll, A. B. (I99I). The piramid of corporate social responsibility: toward the moral management of organizacional stakeholders. Business Horizont, 34(4), 39-48.

Elkington, J. (200I). Canibais com garfo e faca. São Paulo: Makron Books.

Fernández, E., Junquera, B., \& Ordiz, M. (2003). Organizational culture and human resources in the environmental issue: a review of the literature. The International Journal of Human Resource Management, 14(4), 634-656.

González-Benito, J., \& González-Benito O. (2006). A review of determinant factors of environmental proactivity. Business Strategy and the environment, 15, 87-102.

Harris L. C., \& Crane A. (2002). The greening of organizational culture: management views of the depth, degree and diffusion change. Journal of Organization Change Management, 15(3), 214-234.

Hind, P., Wilson, A., \& Lenssen, G. (2007). Developing leaders for sustainable business. Corporate Governance, 9(I), 7-20.

Hoffman, A. J. (I993). The importance of fit between individual values and organizational culture in the greening of industry. Business Strategy and the Environment, 2(4), IO-I8.

Hutchins, M. J., \& Sutherland, J. W. (2008). An exploration of measures of social sustainability and their application to supply chain decisions. Journal of Cleaner Production, 16(I5), I688-I698.

International Organization for Standardization (2009). ISO 26000 . Recuperado em 20 setembro, 20I2, de http://www.iso.org/iso/home/standards/iso2600o.htm.

Jabbour, C. J. C., \& Santos, F. C. A. (2008). The central role of human resource management in the search for sustainable organizations. The International Journal of Human Resource Management, 19(I2), 2I33-2I54.

Jackson, S., Renwick, D., Jabbour, C. J. C., \& Muller-Camen, M. (20II). State-of-the-art and future directions for green human resource management: introduction to the special issue. Zeitschrift für Personalforschung (German Journal of Research in Human Resource Mangement), 25, 99-II6.

Jackson, S., \& Seo, J. (2010). The greening of strategic HRM scholarship. Organization Management Journal, 7, 278-290.

Marrewijk, M. V. (2003). Concepts and definitions of CSR and corporate sustainability: between agency and communion. Journal of Business Ethics, 44(2), 95-105.

O'Connor, M., \& Spangenberg, J. H. (2008). A methodology for CSR reporting: assuring a representative diversity of indicators across stakeholders, scales, sites and performance issues. Journal of Cleaner Production, 16(13), I399-I4I5.

Sachs, I. (I993) Estratégias de transição para o século XXI: desenvolvimento e meio ambiente. São Paulo: Stúdio Nobel, Fundap.

Tachizawa, T. (20II). Gestão ambiental e responsabilidade social corporativa: estratégias de negócios focadas na realidade brasileira (p. I23). São Paulo: Atlas.

Tencati, A., Perrini, F., \& Pogutz, S. (2004). New tools to foster corporate socially responsible behavior. Journal of Business Ethics, 53(I-2), I73-190.

Vuontisjarvi, T. (2006). Corporate social reporting in the European context and human resource disclosures: an analysis of finnish companies. Journal of Business Ethics, 69(4), 331-354. 